\title{
Activation of NMDA Receptors Upregulates A Disintegrin and Metalloproteinase 10 via a Wnt/MAPK Signaling Pathway
}

\author{
Xian-Zi Wan, ${ }^{1 *}$ Bei Li,,${ }^{2 *}$ Yi-Chen Li, ${ }^{1}$ Xiang-Ling Yang, ${ }^{1}$ Wei Zhang, ${ }^{1}$ Ling Zhong, ${ }^{1}$ and Shao-Jun Tang ${ }^{2}$ \\ ${ }^{1}$ School of Pharmaceutical Sciences, Sun Yat-Sen University, Guangzhou 510006, Peoples Republic of China, and ${ }^{2}$ Department of Neuroscience and Cell \\ Biology, University of Texas Medical Branch, Galveston, Texas 77555
}

A disintegrin and metalloproteinase 10 (ADAM10) is the constitutive $\alpha$-secretase that governs the nonamyloidogenic pathway of $\beta$-amyloid precursor protein processing and is an attractive drug target for treating Alzheimer's disease. To date, little is known about the mechanism by which ADAM10 is regulated in neurons. Using mouse primary cortical neurons, we show here that NMDA receptor (NMDAR) activation led to upregulation of the genes encoding ADAM10 and $\beta$-catenin proteins. Interestingly, the ADAM10 upregulation was abolished by inhibitors of Wnt/ $\beta$-catenin signaling. Conversely, activation of the Wnt/ $\beta$-catenin signaling pathway by recombinant Wnt3a stimulated ADAM10 expression. We further showed that both the NMDAR- and Wnt3a-induced ADAM10 upregulation was blocked by ERK inhibitors. We suggest that the NMDARs control ADAM10 expression via a Wnt/MAPK signaling pathway.

\section{Introduction}

Amyloid- $\beta(\mathrm{A} \beta)$ peptides $\left(\mathrm{A} \beta_{1-40}\right.$ and $\left.\mathrm{A} \beta_{1-42}\right)$ are the proteolytic products of $\beta$-amyloid precursor protein (APP), and they likely play a central role in the pathogenesis of Alzheimer's disease (AD). $A \beta$ accumulation in the brain has been shown to impair neurotransmitter release, long-term potentiation, synapse formation (Hu et al., 2009), and learning and other cognitive functions (Johnson-Wood et al., 1997). Although APP processing can undergo the amyloidogenic pathway to generate $A \beta$, it may also go through the nonamyloidogenic pathway to block $A \beta$ production and generate soluble $\mathrm{APP} \alpha(\mathrm{sAPP} \alpha)$. sAPP $\alpha$ is known to play neuroprotective and neurotrophic roles (Cheng et al., 2002; Stein et al., 2004). Thus, effective therapeutic approaches could be involved in switching APP processing to the nonamyloidogenic pathway (Dewachter and Van Leuven, 2002).

While the amyloidogenic pathway is mediated by the $\beta$ - and $\gamma$-secretases (BACE1 and presenilin1/2, respectively), the nonamyloidogenic pathway is regulated by the $\alpha$ - and $\gamma$-secretases (Lichtenthaler, 2011). $\alpha$-Secretase is the key proteinase that controls APP

\footnotetext{
Received July 30, 2011; revised Jan. 6, 2012; accepted Jan. 29, 2012.

Author contributions: S.-J.T. designed research; X.-Z.W., B.L., Y.-C.L., and X.-L.Y. performed research; W.Z. contributed unpublished reagents/analytic tools; X.-Z.W., B.L., and L.Z. analyzed data; X.-Z.W., L.Z., and S.-J.T. wrote the paper.

This work was supported by the University of Texas Medical Branch start-up funds and the Whitehall Foundation (S.-J.T.); National Natural Science Foundation of China Grants 30873457 (to L.Z.) and 30873457 (to W.Z.); and Scientific Technology Project of Guangdong Province of China Grants 2008A060202010 and $2010 B 050700019$ (to L.Z.), and 2008A060202010 and 2010B050700019 (to W.Z.).

*X.-Z.W. and B.L. contributed equally to this work.

The authors declare no financial conflicts of interest.

Correspondence should be addressed to either of the following: Dr. Shao-Jun Tang, Department of Neuroscience and Cell Biology, University of Texas Medical Branch, Galveston, TX 77555, E-mail: shtang@utmb.edu; or Dr. Ling Zhong, School of Pharmaceutical Sciences, Sun Yat-Sen University, Guangzhou 510006, Peoples Republic of China, E-mail: Isszhl@mail.sysu.edu.cn.

DOI:10.1523/JNEUROSCI.3916-11.2012

Copyright $\odot 2012$ the authors $\quad 0270-6474 / 12 / 323910-07 \$ 15.00 / 0$
}

processing in the nonamyloidogenic pathway. A disintegrin and metalloproteinase (ADAM) family, including ADAM9, ADAM10, and ADAM17, constitutes the main $\alpha$-secretase candidates (Lichtenthaler, 2011). Among them, ADAM10 is the primary endogenous $\alpha$-secretase (Jorissen et al., 2010; Kuhn et al., 2010). Evidence from both $\mathrm{AD}$ mouse models and $\mathrm{AD}$ human patients suggests the involvement of $\mathrm{ADAM} 10$ in the regulation of $\mathrm{AD}$ pathogenesis (Epis et al., 2010; Kim et al., 2010). In addition to APP processing, ADAM10 is involved in the shedding of many other biologically important proteins (e.g., Notch, N-cadherin, and Nectin-1) from cell membranes (Hartmann et al., 2002; Uemura et al., 2007; Kim et al., 2010).

Our understanding of the mechanisms that regulate ADAM10 activity in neurons is limited. ADAM10 may be regulated at multiple levels, including mRNA translation (Lammich et al., 2010) and processing of the pro-ADAM10 (Anders et al., 2001). Retinoic acid receptors can increase the expression of ADAM10, leading to a decrease in $\mathrm{A} \beta$ peptides (Tippmann et al., 2009; Donmez et al., 2010). The activity of ADAM10 is regulated by NMDA receptors (NMDARs), which modulate synaptic trafficking of ADAM10 via synapse-associated protein-97 (SAP97) (Marcello et al., 2007). Interference of the interaction between ADAM10 and SAP97 causes sporadic AD (Epis et al., 2010).

In the current study, we found that NMDAR activation increased ADAM10 protein expression in primary cortical cultures. Furthermore, we also revealed that this NMDARregulated ADAM10 protein expression was mediated by Wnt and MAPK/ERK signaling. Our findings uncover novel molecular mechanisms that control synaptic activity-induced synthesis of ADAM10.

\section{Materials and Methods}

Primary cortical cultures. Primary cortical cultures from mouse embryos of either sex were prepared as described previously (Hoey et al., 2009). Briefly, cortices were dissected from C57BL/6J mouse embryos (E18) and 
A

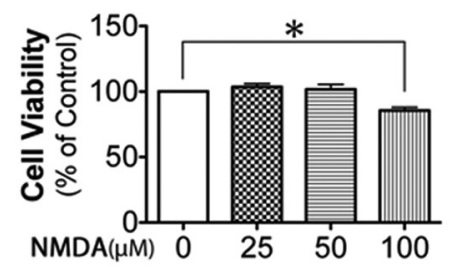

D

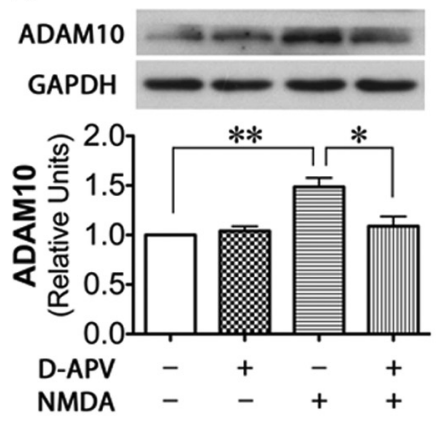

B

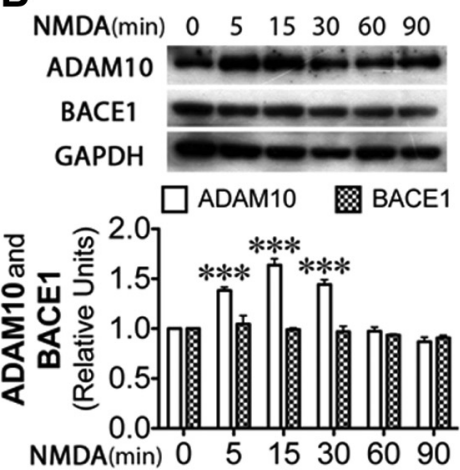

E
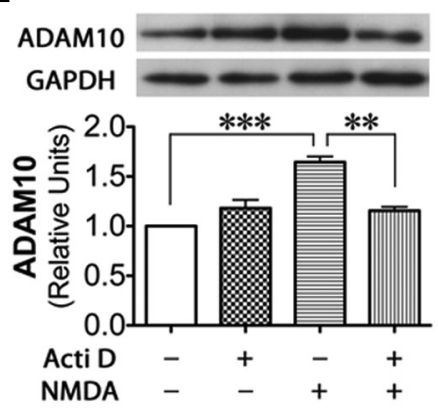

G

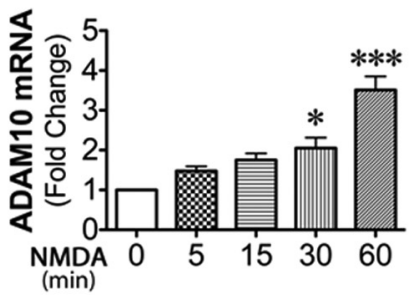

C

$\operatorname{NMDA}(\min ) \quad 0 \quad 5 \quad 15 \quad 30 \quad 60 \quad 90$

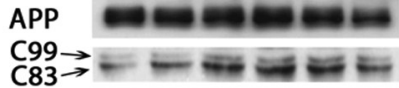

GAPDH

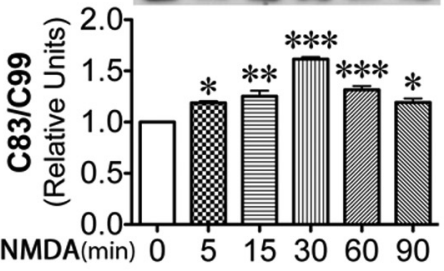

$\mathbf{F}$

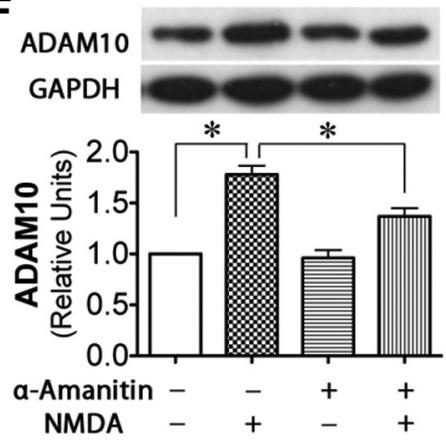

Figure 1. NMDAR activation increases ADAM10 protein in cortical cultures. $\boldsymbol{A}$, NMDA toxicity. Cultures were treated with NMDA for $90 \mathrm{~min}$, and cell viability was measured by MTT $24 \mathrm{~h}$ later. $\boldsymbol{B}$, NMDA-induced ADAM10 upregulation. Cortical cultures (10DIV) were stimulated with $50 \mu \mathrm{m} \mathrm{NMDA,} \mathrm{and} \mathrm{cell} \mathrm{lysates} \mathrm{were} \mathrm{analyzed} \mathrm{by} \mathrm{immunoblotting} \mathrm{with} \mathrm{BACE1} \mathrm{or} \mathrm{ADAM10} \mathrm{antibody} \mathrm{(} n=5$, ${ }^{* * *} p<0.001$ vs 0 min). C, NMDA-induced $\alpha$-secretase activity revealed by immunoblotting of APP-CTFs (C83 and C99) $\left({ }^{*} p<0.05,{ }^{* *} p<0.01,{ }^{* * *} p<0.001\right.$ vs 0 min). D, D-APV blocks NMDA-induced ADAM10. Cultures preincubated with $100 \mu \mathrm{m} \mathrm{D}-A P V$ for 30 min were treated with $50 \mu \mathrm{m} \mathrm{NMDA} \mathrm{for} 15 \mathrm{~min}(n=4)$. E, Effect of actinomycin D on NMDA-induced ADAM10. Cultures were treated with $25 \mu \mathrm{m}$ actinomycin D for $30 \mathrm{~min}$ before NMDA administration ( $15 \mathrm{~min}$ ); both actinomycin D and NMDA were dissolved in $0.1 \%$ DMSO, and cultures treated with $0.1 \%$ DMSO were used as controls $(n=3)$. The signal intensity of the bands on immunoblots was normalized to GAPDH. $\boldsymbol{F}$, Effect of $\alpha$-amanitin on NMDA-induced ADAM10. G, NMDA-regulated ADAM10 transcription. Cultures were treated with $50 \mu \mathrm{m}$ NMDA. The mRNA level of ADAM10 was measured by quantitative PCR and normalized to $\beta$-actin mRNA $\left(n=4,{ }^{*} p<0.05\right.$, ${ }^{* * *} p<0.001$ vs 0 min).

washed in HBSS (Invitrogen). Meninges and excess white matter were removed. Cortical slices $\left(\sim 0.5 \mathrm{~mm}^{2}\right)$ were prepared with microscopic pinches and transferred to a sterile tube containing HBSS. Cortical slices were treated with $0.25 \%$ trypsin (Sigma) for $8 \mathrm{~min}$ at $37^{\circ}$ and were dissociated to single-cell suspension, followed by centrifugation at $120 \times g$ for $5 \mathrm{~min}$. The cell pellets were resuspended in DMEM (Invitrogen) containing $10 \% \mathrm{FBS}$ and $1 \%$ penicillin-streptomycin (Weijia). Cells were planted on culture plates coated with $20 \mu \mathrm{g} / \mathrm{ml}$ poly-D-lysine (Sigma) in $0.1 \mathrm{~m}$ borate buffer, $\mathrm{pH} 8.5\left(50 \mathrm{~mm} \mathrm{H}_{3} \mathrm{BO}_{3}, 12.5 \mathrm{~mm} \mathrm{Na}_{2} \mathrm{~B}_{4} \mathrm{O}_{7}\left(10 \mathrm{H}_{2} \mathrm{O}\right)\right)$. Two hours later, DMEM was replaced with Neurobasal Medium (Invitrogen) supplemented with $2 \%$ B27 (Invitrogen), 1\% penicillinstreptomycin, and $0.5 \mathrm{~mm}$ L-glutamine (Invitrogen). Cells were cultured at $37^{\circ}$ in a humidified incubator of $95 \%$ air and $5 \% \mathrm{CO}_{2}$. One-third of the medium was replenished every $3 \mathrm{~d}$ until $10 \mathrm{~d}$ in vitro (DIV). Under our culturing conditions, $90 \%$ of the cells were neurons, as revealed by MAP2 staining.

MTT assay. Cortical cultures in 96-well plates at 9DIV were treated with NMDA for $90^{\prime}$, followed by continued culturing in fresh medium for $24 \mathrm{~h}$. For MTT assays, $20 \mu \mathrm{l} \mathrm{of} 5 \mathrm{mg} / \mathrm{ml}$ MTT (Sigma) was added to individual wells and incubated for $4 \mathrm{~h}$. The water-insoluble formazan was dissolved in dimethyl sulfoxide (DMSO), and the optical absorbance was measured at $490 \mathrm{~nm}$ using Multiskan Ascent.

Antibodies. Millipore); mouse monoclonal $\beta$-catenin antibody (1: 1000, Cell Signaling Technology); rabbit APP C-terminal antibody (1: 8000, Sigma); mouse monoclonal BACE1 antibody (1:1000, R\&D Systems); mouse monoclonal $p$-ERK1/2 antibody (1:500, Santa Cruz Biotechnology); rabbit ERK1 antibody (1:500, Santa Cruz Biotechnology); rabbit ERK2 antibody (1:500, Santa Cruz Biotechnology); mouse monoclonal GAPDH antibody (1:1000, Santa Cruz Biotechnology); HRP-conjugated mouse IgG antibody (1:10,000, Pierce); and HRPconjugated rabbit IgG antibody (1:5000, Pierce).

Western blotting and quantification. Cortical cultures (10DIV; $0.5 \times$ $10^{6}$ cells/well on 12 -well plates) were lysed with $100 \mathrm{ml}$ of $2 \times$ SDS sample buffer (62.5 mm Tris- $\mathrm{HCl}$ buffer, $\mathrm{pH} 6.8,10 \%$ glycerol, $2 \%$ SDS, 5\% $\beta$-mercaptoethanol, and $0.01 \%$ bromophenol blue). Lysates were transferred to $1.5 \mathrm{ml}$ Eppendorf tubes, boiled for $10 \mathrm{~min}$, and centrifuged at $13,400 \times g$ at $4^{\circ}$ for $5 \mathrm{~min}$. Total protein $(40 \mu \mathrm{g})$ was loaded on $10 \%$ SDS-PAGE. After electrophoresis, the protein was transferred to a 0.2 $\mu \mathrm{m}$ polyvinylidene fluoride membrane (Millipore). The membrane with transferred protein was blocked with $5 \%$ skim milk in TBS-T $(20 \mathrm{~mm}$ 
A

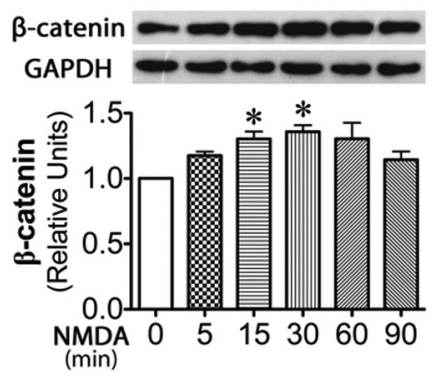

D

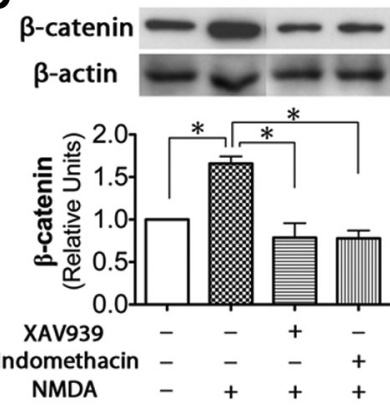

B
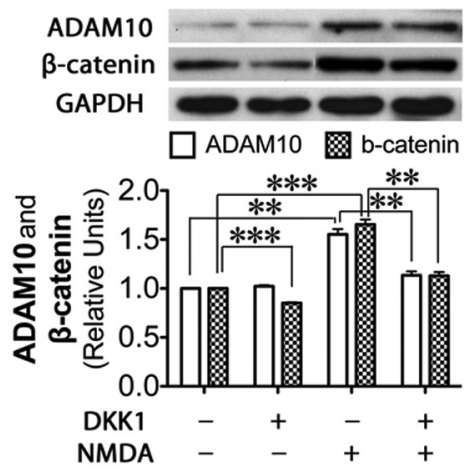

E

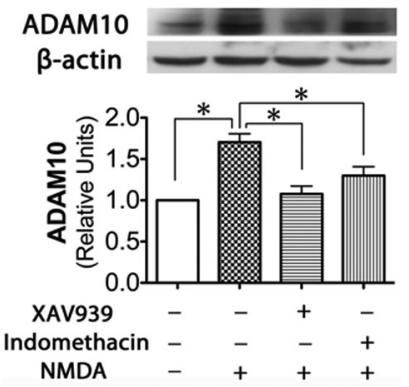

G
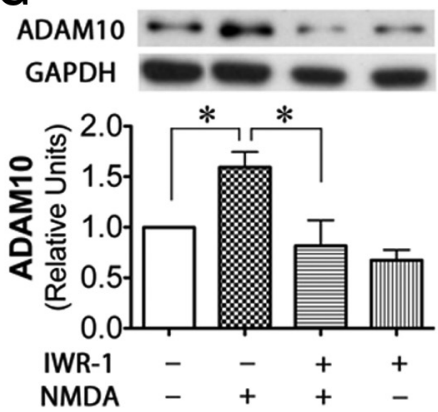

C
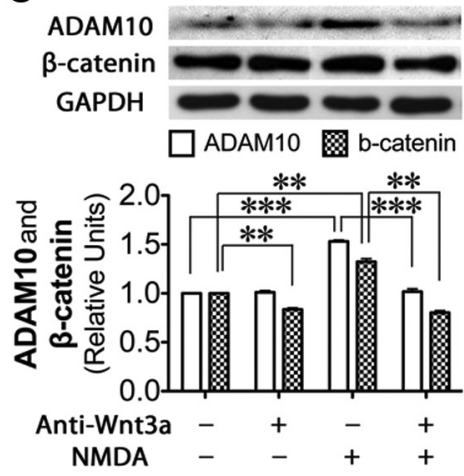

F
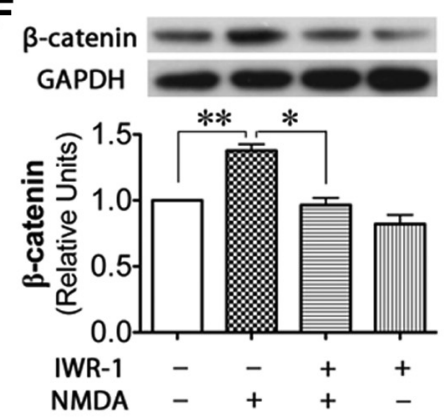

Figure 2. Blockage of Wnt/ $\beta$-catenin signaling inhibits NMDAR-dependent ADAM10 expression. A, NMDA stimulation caused $\beta$-catenin increase. Cortical cultures were stimulated with $50 \mu \mathrm{m}$ NMDA before immunoblotting $\left(n=5 ;{ }^{*} p<0.05\right.$ vs 0 min). $B$, DKK1 impaired NMDA-induced ADAM10 increase. Cultures were treated with or without DKK1 and/or NMDA. When cotreated with both, cultures were pretreated with $100 \mathrm{ng} / \mathrm{ml}$ DKK1 for $60 \mathrm{~min}$ before NMDA administration $(50 \mu \mathrm{m} ; 15 \mathrm{~min})(n=4)$. C, Anti-Wnt3a antibody diminished NMDA-induced ADAM10 increase. Wnt3a antibody was used to neutralize Wnt3a in the medium. $(n=3)$. $\boldsymbol{D}$, Indo $(50 \mu \mathrm{m}, 30 \mathrm{~min})$ and XAV939 (1 $\mu \mathrm{m}, 30 \mathrm{~min})$ abolish NMDA-induced $\beta$-catenin increase. ( $(n=3)$. $\boldsymbol{E}$, Indo $(50 \mu \mathrm{m}, 30 \mathrm{~min})$ and XAV939 (1 $\mu \mathrm{M}, 30 \mathrm{~min}$ ) abolish NMDA-induced ADAM10 upregulation $(n=3)$. $\boldsymbol{F}, \mathbf{G}$, Effects of IWR-1 (10 $\mu \mathrm{m}, 30 \mathrm{~min})$ on NMDA-induced $\beta$-catenin and ADAM10, respectively.

Tris- $\mathrm{HCl}, \mathrm{pH} 7.4,0.15 \mathrm{M} \mathrm{NaCl}, 0.1 \%$ Tween 20 ) for $2 \mathrm{~h}$ at room temperature (RT), incubated with primary antibodies in blocking solution overnight at $4^{\circ}$, and washed with TBST $(3 \times 10 \mathrm{~min})$. After incubating with HRP-conjugated anti-mouse or rabbit secondary antibodies ( $1 \mathrm{~h}$ at RT) and washing, protein bands were detected with an ECL kit (Pierce), according to manufacturer's instructions. The optical density of each band was quantified using Quantity One 4.6.2 (Bio-Rad).

Quantitative RT-PCR. Cortical cultures (10DIV) were stimulated with $50 \mu \mathrm{M}$ NMDA. Total RNA was purified from the cultures with TRIZOL (Invitrogen) according to the manufacturer's instructions. Total RNA $(0.5 \mu \mathrm{g})$ was used for reverse transcription, followed by quantitative real-time PCR using PrimeScript RT reagent kit (TaKaRa). Real-time PCRs [ $25 \mu$ l mixture, which contains $12.5 \mu$ l of $2 \times$ SYBR Premix Ex Taq, $0.5 \mu \mathrm{l}$ of PCR forward primer $(10 \mu \mathrm{M}), 0.5 \mu \mathrm{l}$ of PCR reverse primer (10 $\mu \mathrm{M}), 9.5 \mu \mathrm{l}$ of $\mathrm{H}_{2} \mathrm{O}$, and $2 \mu \mathrm{l}$ of $\mathrm{cDNA}$ ] were performed with the iQ5 system (Bio-Rad; cycling protocol: preincubation at $95^{\circ} \mathrm{C}$ for $30 \mathrm{~s}$ followed by 40 cycles of $95^{\circ} \mathrm{C} / 5 \mathrm{~s}$ and $60^{\circ} \mathrm{C} / 20 \mathrm{~s}$ ). Primer sequences were as follows: ADAM10 reverse primer: $5^{\prime}$-ACCACTGAACTGCTTGCTCCAC-3'; ADAM10 forward primer: 5'-TTATGCCATGTTTGCTG CATGA-3'; $\beta$-actin reverse primer: 5'-GCAATGCCTGGGTACATG-
GTGG-3'; $\beta$-actin forward primer: $5^{\prime}$-ACGCGTCGACCTCCTTGCAGTCCATTTT-3'.

Statistical analysis. Data in summary graphs (mean \pm SEM) were from at least three independent experiments. One-way ANOVA was performed with SPSS 16.0.

\section{Results}

NMDAR activation increases ADAM10 protein

NMDAR activation is known to stimulate $\alpha$-secretase activity, which is responsible for shedding APP and other membrane proteins (Uemura et al., 2007; Hoey et al., 2009). Because ADAM10 is the primary candidate of $\alpha$-secretase (Jorissen et al., 2010; Kuhn et al., 2010), we tested the hypothesis that ADAM10 synthesis is regulated by NMDARs. Cultures were stimulated with different concentrations of NMDA. Stimulation with up to $50 \mu \mathrm{M}$ NMDA did not change cell viability (Fig. $1 A$ ). After stimulation with 50 $\mu \mathrm{M}$ NMDA, ADAM10 and APP protein levels were measured by Western blotting analysis. NMDA caused a rapid transient increase of ADAM10 protein, which peaked with a 1.7-fold increase at $15 \mathrm{~min}$ 
A

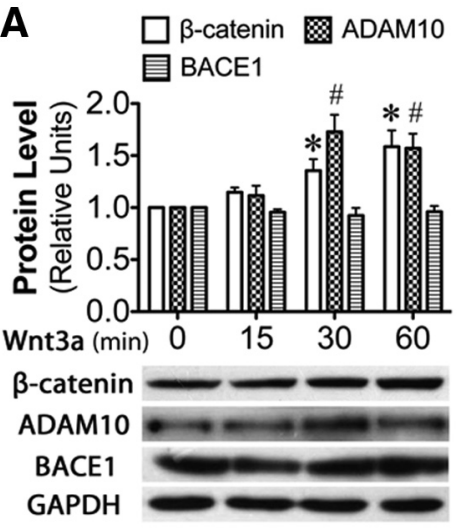

B
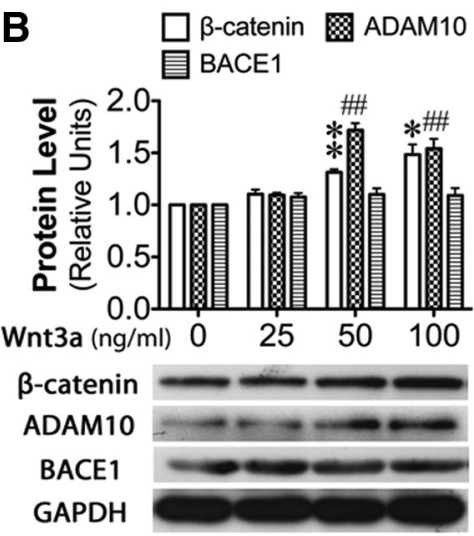

Figure 3. Wnt3a induces ADAM10 expression. $\boldsymbol{A}$, Time course of Wnt3a-induced ADAM10 expression. Immunoblots of $\beta$-catenin, BACE1, and ADAM10 from cultures treated with recombinant Wnt $3 \mathrm{a}(100 \mathrm{ng} / \mathrm{ml})$ for various time $\left[n=4,{ }^{*} p<0.05 \mathrm{vs}\right.$ 0 min $\left(\beta\right.$-catenin); ${ }^{\#} p<0.05$ vs 0 min (ADAM10)]. B, Dose effect of Wnt3a on ADAM10 expression. Immunoblots of $\beta$-catenin, BACE1, and ADAM10 from cultures treated with different amounts of recombinant Wnt $3 \mathrm{a}\left[n=4,{ }^{*} p<0.05,{ }^{* *} p<0.01\right.$ vs 0 min ( $\beta$-catenin); ${ }^{\# \#} p<0.01$ vs 0 min (ADAM10)].

after NMDA administration and returned to basal level by $60 \mathrm{~min}$ (Fig. $1 B$ ). On the other hand, NMDA stimulation did not change BACE1 (Fig. $1 B$ ), suggesting that NMDA stimulation specifically upregulated $\alpha$-secretase ADAM10. Because ADAM10 is a major $\alpha$-secretase in APP processing, we sought to determine whether NMDA stimulation also elevated the $\alpha$-cleavage of APP processing. To this end, immunoblotting was performed to measure the levels of C-terminal fragments (CTFs) of APP. The results showed that the ratio between C83-CTF (an AAP processing product from $\alpha$-cleavage mediated by $\alpha$-secretase) and C99 (an AAP processing product from $\beta$-cleavage) was elevated following NMDA stimulation (Fig. 1C). This result suggested that NMDAR activation facilitated $\alpha$-cleavage, which was consistent with the findings reported earlier (Hoey et al., 2009). Interestingly, although NMDA stimulation promoted the APP $\alpha$-cleavage, we did not observe significant concomitant decrease of full-length APP (Fig. 1C), probably because only a small fraction of APP was processed.

To confirm that the observed effect was mediated by NMDARs, we determined the effect of NMDA in the presence of D-APV $(100 \mu \mathrm{M}$, pretreated for $30 \mathrm{~min})$, a specific antagonist of NMDARs. D-APV abolished NMDA-induced ADAM10 increase (Fig. 1D).

To determine whether NMDA stimulates ADAM10 protein upregulation by transcription activation, we tested the effect of actinomycin D, a transcription inhibitor. As shown in Fig. $1 E, 25 \mu \mathrm{M}$ actinomycin D abolished NMDA-induced ADAM10 increase. Another transcription inhibitor, $\alpha$-amanitin, showed a similar effect (Fig. 1F). These results suggest that NMDAR-activation elicited ADAM10 protein synthesis by activating ADAM10 gene transcription. To investigate this possibility further, we measured the level of ADAM10 mRNA by quantitative real-time RT-PCR, and observed that ADAM10 mRNA was upregulated by NMDA in a time-dependent manner (Fig. $1 G$ ). It appeared that the significant increase of ADAM10 protein (Fig. $1 B$ ) preceded that in mRNA (Fig. 1G). This discrepancy is probably due to NMDAstimulated rapid translation from pre-existing mRNA, as suggested by previous studies (Ouyang et al., 1999; Gong et al., 2006; Li et al., 2012). Also, the ADAM10 protein increase is more transient that the increase of ADAM10 mRNA (Fig. $1 B, G$ ), indicating that there probably is a negative feedback mechanism that tightly controls ADAM10 protein level.

\section{Blockage of Wnt/ $\beta$-catenin signaling inhibits NMDAR-dependent ADAM10 upregulation}

Previous studies indicate that NMDAR activation leads to Wnt release and nuclear accumulation of $\beta$-catenin in hippocampal slices (Chen et al., 2006). Because both NMDAR activation (Hoey et al., 2009; Tampellini et al., 2009) and $\mathrm{Wnt} / \beta$-catenin signaling (De Ferrari et al., 2003) have protective effects on AD pathologies, we tested whether NMDAR activation stimulated ADAM10 synthesis via $\mathrm{Wnt} / \beta$-catenin signaling. To this end, we first determined the effect of NMDA stimulation on $\beta$-catenin in cortical cultures. As shown in Fig. $2 A, \beta$-catenin protein started to elevate at $5 \mathrm{~min}$ and last until $30 \mathrm{~min}$ after $50 \mu \mathrm{M}$ NMDA application, indicating that NMDAR activation resulted in upregulation of $\beta$-catenin signaling in cortical cultures. This NMDA-stimulated $\beta$-catenin increase was blocked by pretreatment with $100 \mathrm{ng} / \mathrm{ml}$ recombinant DKK1 protein (a specific endogenous antagonist for the $\mathrm{Wnt} / \beta$-catenin signaling) at 60 min before NMDA administration (Fig. 2 B), indicating that NDMAR stimulation activated this pathway. Next, we investigated whether NMDA-stimulated ADAM10 expression was the result of the NMDA-induced upregulation of Wnt/ $\beta$-catenin signaling. DKK1 diminished the ADAM10 increase induced by NMDA (Fig. $2 B$ ). Since NMDAR activation causes the secretion of Wnt3a (Chen et al., 2006), which is a prototypic Wnt ligand for the Wnt/ $\beta$-catenin pathway, we specifically tested the involvement of Wnt3a in NMDA-induced ADAM10 upregulation. In this experiment, we used Wnt3a antibody to neutralize Wnt3a. As shown in Fig. 2C, the Wnt3a antibody completely abolished the ADAM10 increase. The inhibitory activity of the antibody on $\mathrm{Wnt} / \beta$-catenin signaling was verified by its blockage of NMDAinduced $\beta$-catenin upregulation (Fig. $2 C$ ).

Next, we performed experiments to test the role of $\beta$-catenin, using pharmacological approaches. Indomethacin (Indo) and XAV939, two different inhibitors of $\beta$-catenin expression (Goessling et al., 2009; Huang et al., 2009), were used in these experiments. The cultures were pretreated with Indo $(50 \mu \mathrm{M})$ or XAV939 $(1 \mu \mathrm{M})$ for $30 \mathrm{~min}$, followed by NMDA (50 $\mu \mathrm{M})$ stimulation for $15 \mathrm{~min}$ before harvesting for immunoblotting. The results showed that treatments of cortical cultures with either inhibitor completely blocked NMDAinduced $\beta$-catenin increase (Fig. $2 D$ ). Importantly, these inhibitors also abolished the NMDA-induced ADAM10 increase (Fig. 2E). These observations were further confirmed with another recently developed small molecule (IWR-1) that promotes $\beta$-catenin degradation by abrogating Axin 2 turnover (Chen et al., 2009) (Fig. 2 F, G). Collectively, these results suggest that the Wnt/ $\beta$-catenin signaling is critical for NMDAstimulated ADAM10 synthesis.

\section{Wnt3a stimulates ADAM10 increase}

The results described above indicate that secretion of Wnt 3 a following NMDAR activation is required for NMDAR-elicited ADAM10 increase. Next, we sought to investigate whether Wnt3a is able to stimulate ADAM10 expression. To this end, we determined the time course and dose effects of Wnt3a on ADAM10 protein level. As 


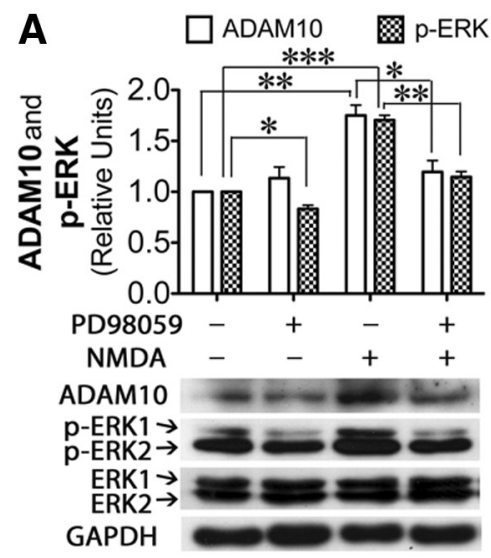

D

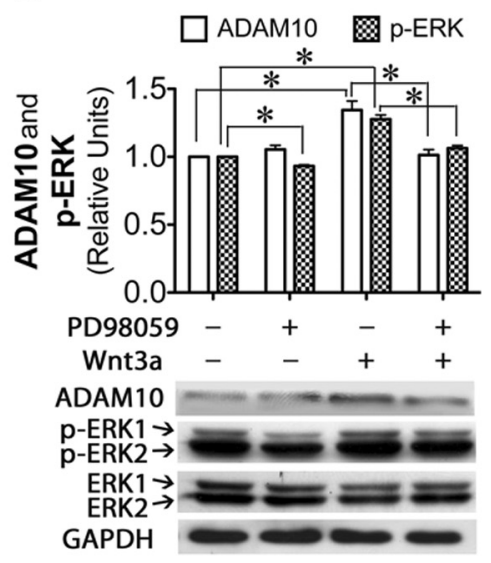

C

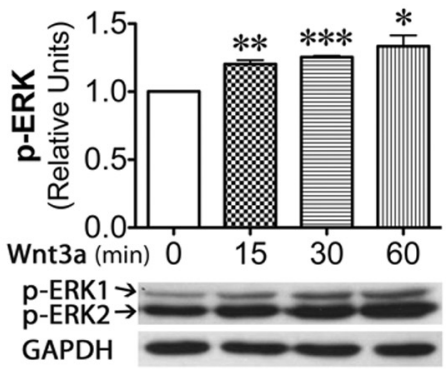

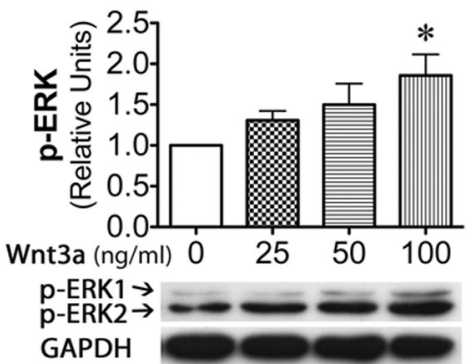

E NMDA

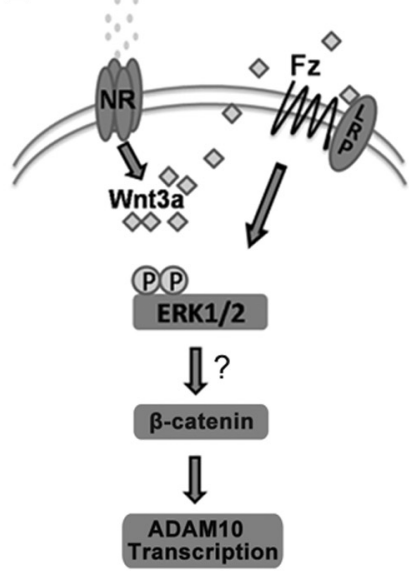

Figure 4. MAPK/ERK pathway is involved in ADAM10 regulation. A, PD98059 blocked NMDA-induced ADAM10 increase. When cotreated with PD98059 and NMDA, PD98059 (20 $\mu \mathrm{M})$ was applied $30 \mathrm{~min}$ before NDMA $(50 \mu \mathrm{M})$, followed by an additional $15 \mathrm{~min}$ of coincubation before cell harvest for immunoblotting. Both PD98059 and NDMA were dissolved in 0.05\% DMSO, which was used in vehicle controls $\left(n=4\right.$; both $p$-ERK1 and $p$-ERK2 were included in quantification). $\boldsymbol{B}$, $\boldsymbol{C}$, Time course $(\boldsymbol{B})$ and dose effect $(\boldsymbol{C})$ of Wnt3a on ERK phosphorylation $\left(n=4\right.$; ${ }^{*} p<0.05$, ${ }^{* *} p<0.01$, ${ }^{* * *} p<0.001$ vs 0 min or $0 \mathrm{ng} / \mathrm{ml}$ ). D, PD98059 inhibited Wnt3a-induced ADAM10 increase. When cotreated with both PD98059 and Wnt3a, cultures were preincubated with PD98059 (20 $\mu \mathrm{m}$ ) for $30 \mathrm{~min}$ before adding Wnt3a $(100 \mathrm{ng} / \mathrm{ml})$, and coincubation was continued for $60 \mathrm{~min}$ before cell harvest for immunoblotting. DMSO (0.05\%) was used as vehicle for both PD98059 and Wnt3a and in control treatment $(n=3)$. $\boldsymbol{E}$, A model of NMDAR/Wnt/MAPK signaling in the regulation of ADAM10 expression. NMDAR activation stimulates the secretion of Wnt3a, which then activates ERKs to elicit ADAM10 expression, likely via $\beta$-catenin.

shown in Fig. $3 A$, addition of recombinant Wnt3a to cultures caused a time-dependent increase of $\beta$-catenin, demonstrating the activity of the purified Wnt $3 \mathrm{a}$ in activating the $\mathrm{Wnt} / \beta$-catenin pathway. Importantly, ADAM10 protein was also elevated by Wnt3a; the ADAM10 increase peaked at $30 \mathrm{~min}$ after Wnt3a application (Fig. $3 A$ ). In dosage experiments, we measured ADAM10 protein levels in cortical cultures treated with various concentrations $(0,25,50$, or $100 \mathrm{ng} / \mathrm{ml}$ ) of recombinant Wnt3a for $60 \mathrm{~min}$. As expected, Wnt3a caused a dose-dependent increase of $\beta$-catenin (Fig. $3 B$ ). Importantly, ADAM10 protein also displayed a similar profile, with a 1.7fold increase at $100 \mathrm{ng} / \mathrm{ml}$ Wnt3a (Fig. 3B). In contrast, Wnt3a treatment did not change BACE1 (Fig. $3 A, B$ ). Together, these results show that Wnt3a is sufficient to specifically induce the upregulation of ADAM10 protein.

Both NMDAR- and Wnt3a-dependent ADAM10 increases are mediated by the MAPK/ERK pathway

We sought to further understand the potential mechanism by which NMDARs and Wnt3a regulate ADAM10. Because the MAPK pathway is critically involved in NMDAR-regulated protein synthesis (Kelleher et al., 2004; Gong and Tang, 2006; Wayman et al., 2006) and major components in the MAPK signaling cascades (including $\mathrm{p} 38$, JNKs and ERKs) are regulated by Wnt signaling (Yun et al., 2005; Bikkavilli and Malbon, 2009), we investigated the role of MAPK signaling in NMDAR- and Wnt3aregulated ADAM10 expression. As shown in Fig. 4A, NMDA stimulation activated the MAPK/ERK pathway, as indicated by the increase of phosphorylated ERK1/2. Importantly, pretreatment of the cultures with a specific ERK inhibitor, PD98059 (20 $\mu \mathrm{M}$ ), blocked NMDAR-induced ADAM10 increase (Fig. 4A). These results indicate that ERK is critical for the upregulation of ADAM10 by NMDARs. Next, we investigated whether MAPK/ ERK signaling was also involved in Wnt3a-stimulated ADAM10 upregulation. We observed that Wnt3a administration also stimulated ERK1/2 phosphorylation in a time- and dose-dependent manner (Fig. 4B,C). Furthermore, PD98059 abolished Wnt3ainduced ADAM10 upregulation (Fig. $4 D$ ). Thus, these observations suggest that NMDA and Wnt3a stimulate the ADAM10 increase via the MAPK/ERK pathway.

\section{Discussion}

We show here that NMDAR activation stimulates ADAM10 protein expression and that this NMDAR-dependent ADAM10 expression is elicited via a Wnt/MAPK/ERK signaling pathway.

Previous studies revealed that synaptic activity stimulated $\alpha$-secretase, and thereby reduced $\mathrm{A} \beta$ generation and release 
(Hoey et al., 2009; Tampellini et al., 2009; Kim et al., 2010). How synaptic activity regulates $\alpha$-secretase remains unclear. Here, we reveal a novel pathway by which NMDARs control ADAM10 activity. Our results revealed that ADAM10 expression was increased by NMDA stimulation and abolished by D-APV (Fig. $1 B, C)$. These observations suggest that synaptic activity may stimulate $\alpha$-secretase activity by upregulation of ADAM10 protein as a result of NMDAR activation.

Our studies further uncover a novel mechanism by which NMDARs regulate ADAM10 expression. Chen et al. (2006) previously reported that NMDAR activation in response to tetanus elicited rapid Wnt3a secretion in hippocampal slices. In support of this notion, stimulation of hippocampal and cortical neurons in cultures by glutamate or NMDA also leads to Wnt3a secretion (unpublished observations). We observed that either DKK1 or Wnt3a antibody blocks NMDAR-induced ADAM10 upregulation (Fig. $2 B, C$ ) and that inhibition of $\beta$-catenin with two different inhibitors abolished the upregulation. Thus, we conclude that the canonical Wnt signaling activated by Wnt3a is critical for NMDAR activation to lead to upregulation of ADAM10.

Furthermore, we showed that exogenous Wnt3a induced ADAM10 expression (Fig. 3). Because NMDAR activation is known to elicit Wnt3a secretion (Chen et al., 2006), this finding suggests that NMDAR activation causes ADAM10 expression by stimulating Wnt3a secretion. Previous work indicates that the canonical Wnt signaling has a protective effect on AD development in animal models (De Ferrari et al., 2003). Our findings of Wnt3a as a positive regulator of the expression of the $\alpha$-secretase ADAM10 suggest that Wnt 3 a may downregulate $\mathrm{A} \beta$ production and thus $\mathrm{A} \beta$ toxicity.

We observed that Wnt3a stimulated ERK activity (Fig. $4 B$ ). Consistent with our findings, prior studies revealed that Wnt3a induced a rapid and $\beta$-catenin-independent activation of ERKs in non-neuronal cells (Yun et al., 2005; Caverzasio and Manen, 2007). Interestingly, ERK inhibitors suppressed not only NMDAR-dependent but also Wnt3a-induced ADAM10 increase (Fig. 4A,D). These findings suggest that the MAPK/ERK signaling is essential for NMDAR and Wnt3a to stimulate ADAM10 expression. Together, we propose that an NMDAR/Wnt/MAPK signaling pathway (Fig. $4 E$ ) controls synaptic activity-regulated expression of ADAM10.

\section{References}

Anders A, Gilbert S, Garten W, Postina R, Fahrenholz F (2001) Regulation of the alpha-secretase ADAM10 by its prodomain and proprotein convertases. FASEB J 15:1837-1839.

Bikkavilli RK, Malbon CC (2009) Mitogen-activated protein kinases and Wnt/beta-catenin signaling: molecular conversations among signaling pathways. Commun Integr Biol 2:46-49.

Caverzasio J, Manen D (2007) Essential role of Wnt3a-mediated activation of mitogen-activated protein kinase p38 for the stimulation of alkaline phosphatase activity and matrix mineralization in C3H10T1/2 mesenchymal cells. Endocrinology 148:5323-5330.

Chen B, Dodge ME, Tang W, Lu J, Ma Z, Fan CW, Wei S, Hao W, Kilgore J, Williams NS, Roth MG, Amatruda JF, Chen C, Lum L (2009) Small molecule-mediated disruption of Wnt-dependent signaling in tissue regeneration and cancer. Nat Chem Biol 5:100-107.

Chen J, Park CS, Tang SJ (2006) Activity-dependent synaptic Wnt release regulates hippocampal long term potentiation. J Biol Chem 281:11910-11916.

Cheng G, Yu Z, Zhou D, Mattson MP (2002) Phosphatidylinositol-3kinase-Akt kinase and p42/p44 mitogen-activated protein kinases mediate neurotrophic and excitoprotective actions of a secreted form of amyloid precursor protein. Exp Neurol 175:407-414.

De Ferrari GV, Chacón MA, Barría MI, Garrido JL, Godoy JA, Olivares G, Reyes AE, Alvarez A, Bronfman M, Inestrosa NC (2003) Activation of
Wnt signaling rescues neurodegeneration and behavioral impairments induced by beta-amyloid fibrils. Molecular psychiatry 8:195-208.

Dewachter I, Van Leuven F (2002) Secretases as targets for the treatment of Alzheimer's disease: the prospects. Lancet Neurol 1:409-416.

Donmez G, Wang D, Cohen DE, Guarente L (2010) SIRT1 suppresses betaamyloid production by activating the alpha-secretase gene ADAM10. Cell 142:320-332.

Epis R, Marcello E, Gardoni F, Vastagh C, Malinverno M, Balducci C, Colombo A, Borroni B, Vara H, Dell'Agli M, Cattabeni F, Giustetto M, Borsello T, Forloni G, Padovani A, Di Luca M (2010) Blocking ADAM10 synaptic trafficking generates a model of sporadic Alzheimer's disease. Brain 133:3323-3335.

Goessling W, North TE, Loewer S, Lord AM, Lee S, Stoick-Cooper CL, Weidinger G, Puder M, Daley GQ, Moon RT, Zon LI (2009) Genetic interaction of PGE2 and Wnt signaling regulates developmental specification of stem cells and regeneration. Cell 136:1136-1147.

Gong R, Tang SJ (2006) Mitogen-activated protein kinase signaling is essential for activity-dependent dendritic protein synthesis. Neuroreport 17:1575-1578.

Gong R, Park CS, Abbassi NR, Tang SJ (2006) Roles of Glutamate Receptors and the Mammalian Target of Rapamycin (mTOR) Signaling Pathway in Activity-dependent Dendritic Protein Synthesis in Hippocampal Neurons. J Biol Chem 281:18802-18815.

Hartmann D, de Strooper B, Serneels L, Craessaerts K, Herreman A, Annaert W, Umans L, Lübke T, Lena Illert A, von Figura K, Saftig P (2002) The disintegrin/metalloprotease ADAM 10 is essential for Notch signalling but not for alpha-secretase activity in fibroblasts. Hum Mol Gen 11:2615-2624.

Hoey SE, Williams RJ, Perkinton MS (2009) Synaptic NMDA receptor activation stimulates $\alpha$-secretase amyloid precursor protein processing and inhibits amyloid- $\beta$ production. J Neurosci 29:4442-4460.

Huang SM, Mishina YM, Liu S, Cheung A, Stegmeier F, Michaud GA, Charlat O, Wiellette E, Zhang Y, Wiessner S, Hild M, Shi X, Wilson CJ, Mickanin C, Myer V, Fazal A, Tomlinson R, Serluca F, Shao W, Cheng H, et al (2009) Tankyrase inhibition stabilizes axin and antagonizes Wnt signalling. Nature 461:614-620.

Hu NW, Klyubin I, Anwy R, Rowan MJ (2009) GluN2B subunit-containing NMDA receptor antagonists prevent Abeta-mediated synaptic plasticity disruption in vivo. Proc Natl Acad Sci U S A 106:20504-20509.

Johnson-Wood K, Lee M, Motter R, Hu K, Gordon G, Barbour R, Khan K, Gordon M, Tan H, Games D, Lieberburg I, Schenk D, Seubert P, McConlogue L (1997) Amyloid precursor protein processing and A beta42 deposition in a transgenic mouse model of Alzheimer disease. Proc Natl Acad Sci U S A 94:1550-1555.

Jorissen E, Prox J, Bernreuther C, Weber S, Schwanbeck R, Serneels L, Snellinx A, Craessaerts K, Thathiah A, Tesseur I, Bartsch U, Weskamp G, Blobel CP, Glatzel M, De Strooper B, Saftig P (2010) The disintegrin/ metalloproteinase ADAM10 is essential for the establishment of the brain cortex. J Neurosci 30:4833-4844

Kelleher RJ 3rd, Govindarajan A, Jung HY, Kang H, Tonegawa S (2004) Translational control by MAPK signaling in long-term synaptic plasticity and memory. Cell 116:467-479.

Kim J, Lilliehook C, Dudak A, Prox J, Saftig P, Federoff HJ, Lim ST (2010) Activity-dependent alpha-cleavage of nectin- 1 is mediated by a disintegrin and metalloprotease 10 (ADAM10). J Biol Chem 285:22919-22926.

Kuhn PH, Wang H, Dislich B, Colombo A, Zeitschel U, Ellwart JW, Kremmer E, Rossner S, Lichtenthaler SF (2010) ADAM10 is the physiologically relevant, constitutive alpha-secretase of the amyloid precursor protein in primary neurons. EMBO J 29:3020-3032.

Lammich S, Buell D, Zilow S, Ludwig AK, Nuscher B, Lichtenthaler SF, Prinzen C, Fahrenholz F, Haass C (2010) Expression of the antiamyloidogenic secretase ADAM10 is suppressed by its $5^{\prime}$-untranslated region. J Biol Chem 285:15753-15760.

Li Y, Li B, Wan X, Zhang W, Zhong L, Tang SJ (2012) NMDA receptor activation stimulates transcription-independent rapid Wnt5a protein synthesis via the MAPK signaling pathway. Molecular Brain 5:1.

Lichtenthaler SF (2011) Alpha-secretase in Alzheimer's disease: molecular identity, regulation and therapeutic potential. J Neurochem 116:10-21.

Marcello E, Gardoni F, Mauceri D, Romorini S, Jeromin A, Epis R, Borroni B, Cattabeni F, Sala C, Padovani A, Di Luca M (2007) Synapse-associated protein-97 mediates $\alpha$-secretase ADAM10 trafficking and promotes its activity. J Neurosci 27:1682-1691. 
Ouyang Y, Rosenstein A, Kreiman G, Schuman EM, Kennedy MB (1999) Tetanic stimulation leads to increased accumulation of $\mathrm{Ca}^{2+}$ / calmodulin-dependent protein kinase II via dendritic protein synthesis in hippocampal neurons. J Neurosci 19:7823-7833.

Stein TD, Anders NJ, DeCarli C, Chan SL, Mattson MP, Johnson JA (2004) Neutralization of transthyretin reverses the neuroprotective effects of secreted amyloid precursor protein (APP) in APPSW mice resulting in tau phosphorylation and loss of hippocampal neurons: support for the amyloid hypothesis. J Neurosci 24:7707-7717.

Tampellini D, Rahman N, Gallo EF, Huang Z, Dumont M, Capetillo-Zarate E, Ma T, Zheng R, Lu B, Nanus DM, Lin MT, Gouras GK (2009) Synaptic activity reduces intraneuronal $\mathrm{A} \beta$, promotes APP transport to synapses, and protects against $\mathrm{A} \beta$-related synaptic alterations. J Neurosci 29:9704-9713.
Tippmann F, Hundt J, Schneider A, Endres K, Fahrenholz F (2009) Upregulation of the alpha-secretase ADAM10 by retinoic acid receptors and acitretin. FASEB J 23:1643-1654.

Uemura K, Kuzuya A, Aoyagi N, Ando K, Shimozono Y, Ninomiya H, Shimohama S, Kinoshita A (2007) Amyloid beta inhibits ectodomain shedding of N-cadherin via down-regulation of cell-surface NMDA receptor. Neuroscience 145:5-10.

Wayman GA, Impey S, Marks D, Saneyoshi T, Grant WF, Derkach V, Soderling TR (2006) Activity-dependent dendritic arborization mediated by CaM-kinase I activation and enhanced CREB-dependent transcription of Wnt-2. Neuron 50:897-909.

Yun MS, Kim SE, Jeon SH, Lee JS, Choi KY (2005) Both ERK and Wnt/betacatenin pathways are involved in Wnt3a-induced proliferation. J Cell Sci 118:313-322. 